\title{
THE MODIFIED HYERS-ULAM-RASSIAS STABILITY OF A CUBIC TYPE FUNCTIONAL EQUATION
}

\author{
ICK-SOON CHANG, KIL-Woung JUn AND Yong-SOO JUNG
}

Abstract. In this paper, we obtain the solution of the following new cubic type functional equation and investigate the modified Hyers-Ulam-Rassias stability of this equation by using the fixed point alternative:

$$
\begin{aligned}
f(x+y+2 z)+f(x+y-2 z)+f(2 x)+f(2 y)+7 f(x)+7 f(-x) \\
=2[f(x+y)+2 f(x+z)+2 f(x-z)+2 f(y+z)+2 f(y-z)] .
\end{aligned}
$$

Mathematics subject classification (2000): 39B72, 39B52.

Key words and phrases: Stability, cubic function, fixed point alternative.

\section{REFERENCES}

[1] J. ACzÉL, J. Dhombres, Functional Equations in Several Variables, Cambridge Univ. Press, 1989.

[2] J. BAKER, The stability of the cosine equation, Proc. Amer. Math. Soc. 80, (1980), 411-416.

[3] I.-S. CHANG, Y.-S. JUNG, Stability of a functional equation deriving from cubic and quadratic functions, J. Math. Anal. Appl. 283, 2 (2003), 491-500.

[4] I.-S. ChAng, E. H. LEE AND H.-M. KIM, On Hyers-Ulam-Rassias stability of a quadratic functional equation, Math. Ineq. Appl. 6, 1 (2003), 87-95.

[5] P. W. CHOLEWA, Remarks on the stability of functional equations, Aequationes Math., 27, (1984), 76-86.

[6] S. CZERWIK, On the stability of the quadratic mapping in normed spaces, Abh. Math. Sem. Univ. Hamburg, 62, (1992), 59-64.

[7] P. GǍVRUTA, A generalization of the Hyers-Ulam-Rassias stability of approximately additive mappings, J. Math. Anal. Appl., 184, (1994), 431-436.

[8] D. H. HyERS, On the stability of the linear functional equation, Proc. Natl. Acad. Sci., 27, (1941), 222-224.

[9] D. H. Hyers, G. IsAC AND TH. M. RAssias, Stability of Functional Equations in Several Variables, Birkhäuser, Basel, 1998.

[10] K.-W. Jun, H.-M. KIM, The generalized Hyers-Ulam-Rassias stability of a cubic functional equation, J. Math. Anal. Appl., 274, 2 (2002), 867-878.

[11] S.-M. Jung, On the Hyers-Ulam stability of the functional equations that have the quadratic property, J. Math. Anal. Appl., 222, (1998), 126-137.

[12] Y.-S. JunG, K.-H. PARK, On the stability of the functional equation $f(x+y+x y)=f(x)+f(y)+$ $x f(y)+y f(x)$, J. Math. Anal. Appl., 274, 2 (2002), 659-666.

[13] PL. KANNAPPAN, Quadratic functional equation and inner product spaces, Results Math., 27, (1995), 368-372.

[14] B. Margolis, J. B. Diaz, A fixed point theorem of the alternative for contractions on a generalized complete metric space, Bull. Amer. Math. Soc., 126, 74 (1968), 305-309.

[15] V. RADU, The fixed point alternative and the stability of functional equations, Seminar on Fixed Point Theory Cluj-Napoca, (to appear in vol. IV on 2003). 
[16] TH. M. Rassias, On the stability of the linear mapping in Banach spaces, Proc. Amer. Math. Soc., 72 , (1978), 297-300.

[17] TH. M. RASSIAS, On the stability of functional equations in Banach spaces, J. Math. Anal. Appl., 251, (2000), 264-284.

[18] TH. M. RASSIAS, On the stability of functional equations and a problem of Ulam, Acta Math. Appl., 62, (2000), 23-130.

[19] TH. M. RAsSIAS (Ed.), Functional Equations and inequalities, Kluwer Academic, Dordrecht/ Boston/ London, 2000.

[20] TH. M. RASSIAS, J. TABOR, What is left of Hyers-Ulam stability?, Journal of Natural Geometry, 1, (1992), 65-69.

[21] F. SKoF, Proprietà locali e approssimazione di operatori, Rend. Sem. Mat. Fis. Milano, 53, (1983), $113-129$.

[22] S. M. Ulam, Problems in Modern Mathematics, Chap. VI, Science ed., Wiley, New York, 1960. 